\title{
Nerve preservation during partial sacrectomy by two-stage anterior and posterior approach: illustrative case
}

\author{
Parménides Guadarrama-Ortíz, MD, ${ }^{1}$ Ingrid Montes de Oca-Vargas, MD, ${ }^{1,2,3}$ José Alberto Choreño-Parra, PhD, ${ }^{1}$ \\ André Garibay-Gracián, MD, ${ }^{1,2,4}$ Deyanira Capi-Casillas, MD, ${ }^{4,5}$ Alondra Román-Villagomez, MD, ${ }^{4,5}$ Citlaltepetl Salinas-Lara, PhD, ${ }^{6}$ \\ Ulises Palacios-Zúñiga, MD, ${ }^{7}$ and Ángel Daniel Prieto-Rivera, $\mathrm{NP}^{1}$
}

\begin{abstract}
${ }^{1}$ Department of Neurosurgery, ${ }^{2}$ Programa de Servicio Social en Investigación, and ${ }^{5}$ Internado Médico de Pregrado, Centro Especializado en Neurocirugía y Neurociencias México (CENNM), Mexico City, Mexico; ${ }^{3}$ Facultad de Estudios Superiores (FES) Iztacala, Universidad Nacional Autónoma de México, Tlalnepantla de Baz, Mexico; ${ }^{4}$ Escuela Nacional de Medicina y Homeopatía, Instituto Politécnico Nacional, Mexico City, Mexico; ${ }^{6}$ Departamento de Neuropatología, Instituto Nacional de Neurología y Neurocirugía "Manuel Velasco Suárez", Mexico City, Mexico; and ${ }^{7}$ Servicio de Neurocirugía, Módulo de Columna, Hospital Regional $1^{\circ}$ de Octubre, Instituto de Seguridad y Servicios Sociales de los Trabajadores del Estado (ISSSTE), Mexico City, Mexico
\end{abstract}

BACKGROUND Preserving the neurological function of sacral nerves during total or partial sacrectomy is challenging.

OBSERVATIONS The authors describe a case of an osseous desmoplastic fibroma of the sacrum in a 51-year-old woman. The patient attended the authors' institution with loss of muscle strength and sensitivity impairment in both legs, gait instability, bowel constipation, urinary incontinence, and weight loss. Preoperative magnetic resonance imaging and positron emission tomography/computed tomography showed intrapelvic and posterior extension of the tumor but sparing of $\mathrm{S} 1$ and the sacroiliac and lumbosacral joints. After a multidisciplinary discussion of the case, a staged anterior-posterior approach to the sacrum was chosen. The abdominal approach allowed full mobilization of the uterus, ovaries, bladder, and colon and protection of iliac vessels. After tumor resection, a synthetic surgical mesh was placed over the sacrum to minimize soft tissue defects. Then, the posterior stage allowed the authors to perform a bicortical osteotomy, achieving wide tumor excision with minimal nerve root injury. Spinopelvic fixation was not necessary, because both sacroiliac and lumbosacral joints remained intact. A few days after the surgery, the patient restarted ambulation and recovered sphincter control.

LESSONS Multidisciplinary planning and a staged abdominal and posterior approach for partial sacrectomy were fundamental to preserve neurological function in this case.

https://thejns.org/doi/abs/10.3171/CASE21384

KEYWORDS en bloc sacrectomy; partial sacrectomy; sacral tumors; sacrum

The sacrum, formed by the fusion of the last five vertebrae and the coccyx, is the terminal part of the spine that stabilizes the trunk by joining the pelvis and the lumbar vertebral column. The nerve roots that emerge through the sacral foramina, together with the lower lumbar nerves, form the sacral plexus (L4, L5, S1, S2, and S3). This plexus gives rise to the sciatic nerve that innervates the ipsilateral leg. Likewise, the sacral nerves form the superior gluteal nerve $(L 4, L 5$, and $S 1)$ that innervates the gluteus medius, minimus, and tensor fasciae latae muscles; the inferior gluteal nerve (L5, S1, and S2) that innervates the gluteus maximus muscle; the pudendal nerve (S2, S3, and S4) that innervates the external urinary/anal sphincters and genitals; and the posterior femoral cutaneous nerve (S1, S2, and S3) that innervates the hip joint, perineum, and lower and medial portions of the gluteal popliteal fossa. Subsequent terminal branches of these nerves include the internal obturator, gemellus superior, inferior hemorrhoidal, levator ani, coccygeal, pelvic splanchnic, piriformis, and quadratus femoris nerves. ${ }^{1,2}$

ABBREVIATIONS CSF = cerebrospinal fluid; $C T$ = computed tomography; $\mathrm{MRI}=$ magnetic resonance imaging; PTFE = polytetrafluoroethylene; SSEP = somatosensory evoked potential.

INCLUDE WHEN CITING Published September 20, 2021; DOI: 10.3171/CASE21384.

SUBMITTED July 1, 2021. ACCEPTED July 20, 2021.

(C) 2021 The authors, CC BY-NC-ND 4.0 (http://creativecommons.org/licenses/by-nc-nd/4.0/). 
All these fibers control the motor, sensitivity, and autonomic functions of the lower abdomen, pelvis, and legs, including the anorectal and bladder sphincters and the function of the sexual organs. Therefore, it is easy to deduce that any surgery that involves removing part or all of the sacrum is extremely challenging due to the high risk of lesioning the peripheral nerves and roots already described. However, these procedures are required for the resection of invasive tumors of the sacrum. Sacral tumors, which represent $5 \%$ of all bone neoplasias, can form in situ or be metastatic in origin, and most are chondromas (22\%), giant cell tumors (15\%), neurofibromas $(11 \%)$, schwannomas $(8 \%)$, and chondrosarcomas $(5 \%),{ }^{3,4}$ all with high morbimortality. As such, sacrectomies are uncommon procedures selected only for cases where surgery can influence outcomes. Thus, surgical approaches to the sacrum are often unknown to most neurosurgeons. Indeed, resection of sacral tumors requires a multidisciplinary team composed of oncological, vascular, plastic, orthopedic, and neurological surgeons. ${ }^{5}$ Extenuating planning of the surgical approach is also needed, individualized according to specific patient characteristics, type and extension of the tumor, and risk of complications, such as bleeding, infection, and neurological sequelae. 6,7

Preserving the neurological function of sacral nerves during sacrectomy is a highly demanding task. In most giant neoplasias affecting the upper part of the sacrum, the nerves are mutilated to achieve complete tumor resection by a total or partial en bloc sacrectomy. ${ }^{8,9}$ Conversely, unilateral or bilateral sparing of S2-4 nerves is not impossible and should be attempted in less complex tumors involving the middle and lower sacrum to increase the probability of maintaining sufficient neurological function. Here we describe a rare case of a sacral desmoplastic fibroma successfully resected using a partial sacrectomy by a two-stage anterior and posterior approach with sparing of all sacral nerves and minimal postoperative morbidity. Although partial sacrectomies have been described in the literature before, the illustrative images and video included in the present report might be of greater benefit for understanding the technical aspects of this procedure through visualization.

\section{Illustrative Case}

\section{Patient's History}

A 51-year-old woman attended our center due to progressive loss of muscle strength in both legs, gait instability, sensitivity impairment of the right lower limb and perineal area, bowel constipation, urinary incontinence, and weight loss (11 kg in 2 months). Her past family history was relevant for diabetes mellitus, cardiovascular disease, and breast cancer in first-degree relatives. Also, she had been diagnosed with rheumatoid arthritis and diabetes 20 years ago, receiving treatment only with gliclazide. She denied any trauma, toxic exposure, alcohol consumption, smoking, or drug abuse. Five months before, she had sought medical attention at another hospital due to an acute onset of generalized pain, sensation of abdominal bloating, anxiety, and sense of impending doom. In that center, she was subjected to an abdominopelvic computed tomography (CT) scan, which revealed ovarian cysts and a pelvic mass infiltrating the sacrum and compressing the sacral nerve roots. A CT-guided biopsy revealed an osseous desmoplastic fibroma (Supplemental Fig. 1). Hence, she was referred to our center for surgical treatment.

On admission, the patient was aware and oriented to person, place, and time. Also, she was able to follow simple commands and name objects. Her vital signs and body mass index $\left(21.4 \mathrm{~kg} / \mathrm{m}^{2}\right)$ were within normal ranges. Her general physical examination revealed no pulmonary, cardiovascular, or hepatic abnormalities but disclosed decreased peristalsis. Also, her neurological examination showed a deviation of the gait to the right, diminished muscle strength, and hyporeflexia in both lower limbs, hypoesthesia in the S1-3 dermatomes, and decreased anal sphincter tone. Meningeal signs were absent. A comprehensive initial laboratory work-up showed normal levels of hemoglobin, erythrocytes, platelets, glucose, and white blood cells. The patient's thyroid, liver, and renal function parameters, as well as her urinalysis, metabolic panel, lipid panel, coagulation panel, erythrocyte sedimentation rate, C-reactive protein, and serum levels of calcium, magnesium, sodium, potassium, and chloride, were within normal ranges.

\section{Planning of Surgery}

A multidisciplinary team was formed that consisted of internists, neurologists, radiologists, nuclear medicine specialists, pathologists, spine surgeons, surgical oncologists, and neurosurgeons. These specialists discussed best therapeutic options based on an extensive analysis of preoperative magnetic resonance imaging (MRI) (Fig. 1A-D), positron emission tomography (Fig. 1E-H), and CT scans with reconstruction of the sacrum and vascular bundles of the pelvis (Fig. 2). These studies revealed that the tumor originated in the sacrum and extended to both the presacral space and the posterior sacral wall, classifying it as a type II sacral tumor according to Klimo et al. ${ }^{7}$ Furthermore, the mass was placed over the right middle to lower body of the sacrum, from the superior edge of the first anterior foramen to the level of the fourth transverse ridge, limited posteriorly within the two lateral sacral crests. An upper part of the tumor was also involving the left S1-2 segments of the sacrum (Fig. 1). Importantly, the tumor spared the base, superior articular facets, promontory, tuberosities, alas, cornu, and hiatus of the sacrum, as well as the coccyx (Fig. 2). Other findings that were considered in the discussion of treatment included the closeness of the tumor to the descending colon and rectum, its vascular relationships, the presence of uterine fibroids with active bleeding, and the absence of bladder infiltration. After 2 months of planning and debate, we decided that the best therapeutic option was wide local surgical excision and partial amputation of the sacrum. This decision was also made considering the young age of the patient and the low malignant potential but high resistance to radiotherapy of this type of tumor. Hence, a two-stage anterior and posterior approach for partial sacrectomy was chosen. The patient was fit for the first-stage abdominal approach by stabilizing her blood glucose levels, preparing the colon with a polyethylene glycol-based solution, and administering antibiotics the day before surgery.

\section{First-Stage Anterior Approach}

The anterior approach was performed with the patient in the supine position and under general anesthesia. Somatosensory evoked potential (SSEP) electrodes were placed for transoperative monitoring of neurological function. The oncology surgical team began the procedure with a regular laparotomy incision and dissection. Then, total hysterectomy and bilateral oophorectomy followed by a left hemicolectomy were performed, leaving the colon segment closed to avoid fecal contamination. The colostomy was finished at the end of this stage. Afterward, ureters and iliac vessels were dissected and referred to avoid posterior injury, and the bladder was referred to the anterior abdominal wall with a suture to protect it 

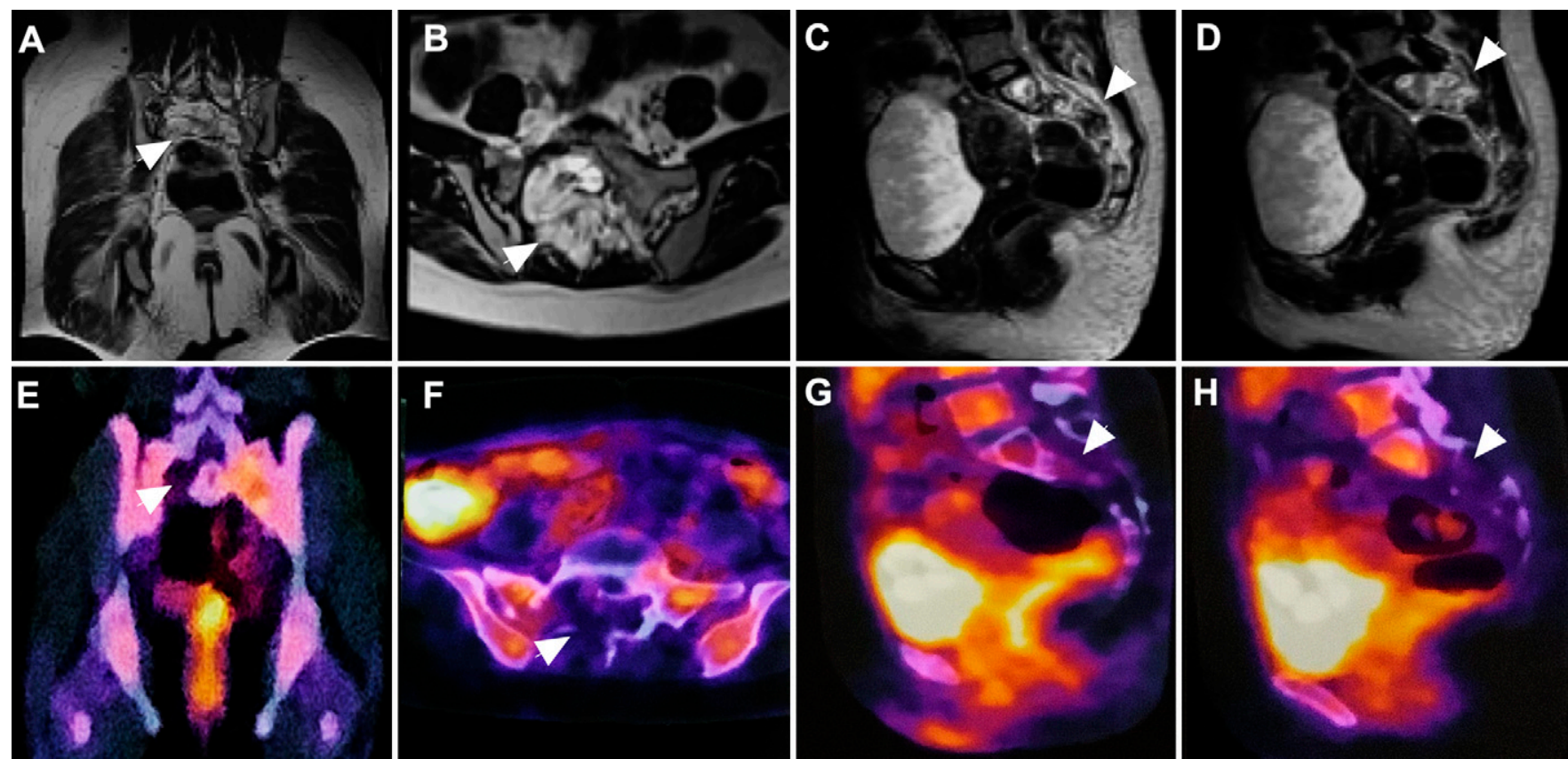

FIG. 1. Preoperative images of the sacral tumor. Contrast-enhanced T1-weighted MRI of the pelvis showing a tumor involving the S2-4 segments of the sacrum (white arrowheads) with abdominal and posterior extension. A: Coronal view. B: Axial view. C and D: Sagittal view. A positron emission tomography/CT scan of the pelvis was also obtained to delimit the tumor, which is shown as an area of hypometabolism within the sacrum (white arrowheads). E: Coronal view. F: Transverse view. G and H: Sagittal view.

(Fig. 3A). The bladder, uterus, and colon were not invaded by the tumor. Nonetheless, their removal provided a broader working area and direct access to the sacrum.
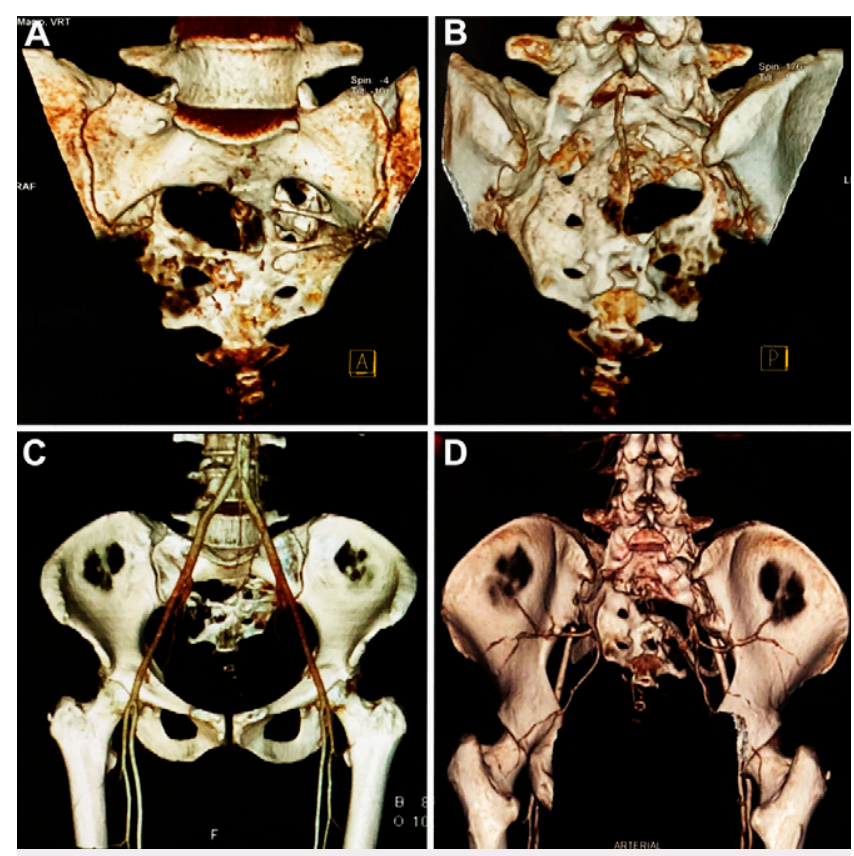

FIG. 2. Preoperative CT scan of the sacrum with three-dimensional bone and vascular reconstruction. A: Anterior view of the sacrum. B: Posterior view of the sacrum. Notice the bone infiltration of the tumor. C: Anterior view of the sacrum with vascular reconstruction. D: Posterior view of the sacrum with vascular reconstruction.
After the surgical field was cleared, the neurosurgical team proceed to the anterior sacrectomy. First, the lumbosacral angle was delimited. Afterward, the tumor invading the S1-4 anterior segments of the sacrum became visible. For tumoral resection, we used an ultrasonic aspirator with a Frasier suction tube protected to limit damage to adjacent nerves. Also, a Midas Rex-IPC (EC 300) drill was employed to remove attachments of the tumor to its bony bed. The sacrum plexus roots were identified and preserved, and the tumor resection continued until the posterior limit of the sacrum was reached (Fig. $3 B$ and $C$ and Video 1). Then, a polytetrafluoroethylene (PTFE) surgical mesh was placed over the sacrum to reduce dead space, minimize soft tissue defects, avoid posterior herniation of abdominal content through its edges, and establish an anterior limit for the posterior approach (Fig. 3D). The colostomy was finished, preserving a distal rectum portion for posterior reconnection of the bowel. The first anterior stage was finished after 8 hours of surgery with total bleeding of $450 \mathrm{~mL}$. During the immediate postoperative period, no complications were observed, and the colostomy was functional. A control lumbosacral bone reconstruction by MRI was performed for planning the second stage.

VIDEO 1. Clip showing a two-stage anterior and posterior approach to the sacrum for sacral tumor resection and nerve preservation. Click here to view.

\section{Second-Stage Posterior Approach}

Thirty-six hours after the first stage, the posterior approach was performed with the patient under general anesthesia and placed in the prone position. SSEP electrodes were placed, and the pelvis was elevated at $25^{\circ}$ to allow the exposure of the sacrum. Then, the surgical team started the procedure with a posterior incision from L5 to S2 

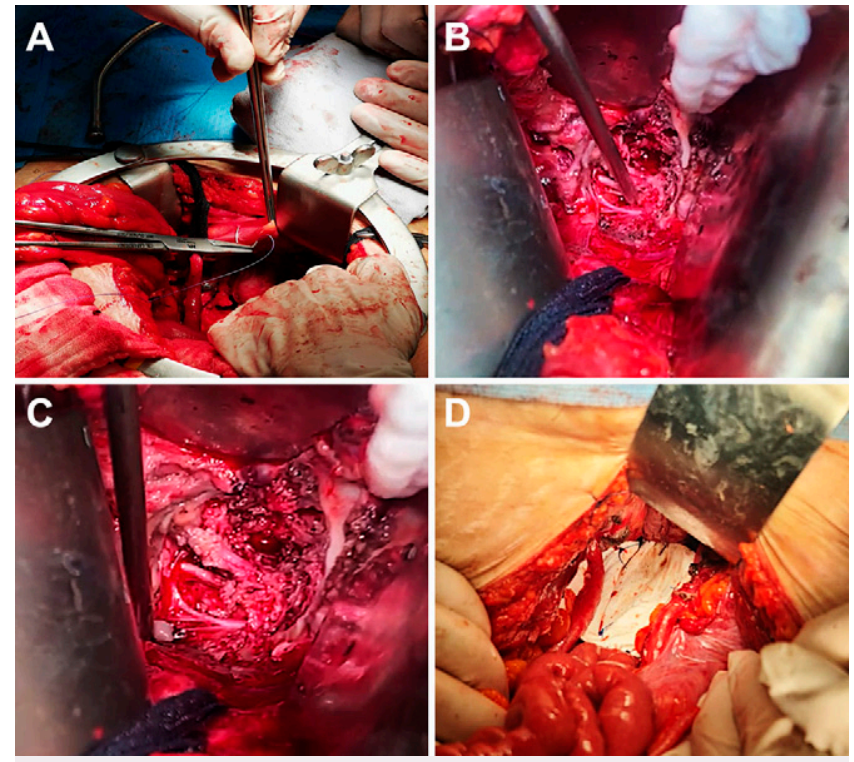

FIG. 3. First-stage anterior approach to the sacrum for tumor resection. A: After a regular laparotomy and dissection, a total hysterectomy, bilateral oophorectomy, hemicolectomy, and reference of iliac vessels, ureters, and bladder were performed. B and C: With the surgical field cleared, the anterior segments of the tumor were removed, protecting the sacral plexus nerve roots. D: A PTFE surgical mesh was placed over the sacrum to reduce dead space and minimize soft tissue defects.

following the medial line and separating skin and subcutaneous tissue pads with Richardson separators (Fig. 4A). The lumbosacral fascia was opened (Fig. 4B); the paraspinal muscles, sacrotuberous, and sacroiliac ligaments were exposed and dissected; and the external parts of the tumor were resected (Fig. 4C-E) until the posterior aspect of the sacrum was visible (Fig. $4 \mathrm{~F}$ and $\mathrm{G}$ ). The sacrectomy was carried out using a Midas Rex-IPC (EC 300) drill, Kerrison bone punches, and Rhoton microdissectors. The remaining posterior part of the tumor was invading the right S1-4 and left S1-2 segments of the sacrum (Fig. 4H).

Once the median and lateral sacral crests were removed, the sacral canal and plexus with its S1-4 roots were exposed (Fig. 4I). These roots were protected with saline-soaked cottonoids while electrocoagulation of some sacral and tumor vessels was carried out. The largest parts of the tumor were resected using an ultrasonic aspirator with Frasier suction tubes, first identifying and preserving nerve roots until we reached the limit of the PTFE mesh placed during the first stage at $15 \mathrm{~cm}$ from the posterior surface (Fig. 4J). To achieve maximum tumor resection, respecting the sacral nerves, sacral arteries, veins, and uninvaded lateral bone margins, a Pentero 900 microscope was introduced to perform microsurgical dissection, thus achieving resection of the deep tumor portions (Fig. 4K and L). During this procedure, the perineurium of the right S2 root was injured but repaired with suture (Fig. 4M). Almost at finishing the surgery, a small cerebrospinal fluid (CSF) leak was found, which was repaired with Beriplast $P$ fibrin sealant (Fig. $4 \mathrm{~N}$ and $\mathrm{O}$ ). Once the posterior sacrectomy was completed, the absence of CSF leak and bleeding was verified. The nerve roots and their immediate branches were freed. We decided not to fixate the pelvis and lumbar spine, because the sacroiliac and lumbosacral joints were spared, leaving intact the pelvic ring and the posterior sacroiliac, iliolumbar, sacrotuberous, and sacrospinous ligaments. Finally, we placed a Gelfoam sponge over the area and closed the operated area by planes (Fig. 4P), finalizing the surgery in 9 hours with a total of $600 \mathrm{~mL}$ of bleeding. The complete second-stage posterior approach to the sacrum is shown in Video 1.

\section{Outcome and Follow-Up}

The patient received antibiotics for an additional 7 days and did not develop any postoperative complication during the follow-up period. The sensitivity and motor function of both lower limbs progressively improved. A few days after the surgery, the patient restarted ambulation and received physical therapy (Video 1). Also, she recovered the control of her anorectal and bladder sphincters despite the colostomy. However, the patient reported anesthesia at the right inner and outer vaginal labia, innervated by the genital nerve. Postoperative images of the sacrum showed no residual tumor (Fig. 5A and B). Of note, the patient showed no instability of the pelvis and lumbar spine (Fig. 5C-F). The histopathological analysis of the resected tumor confirmed the diagnosis of an osseous desmoplastic fibroma (Supplemental Fig. 2).

\section{Discussion}

\section{Observations}

In this report, we describe an illustrative case of a sacral tumor that was removed via a staged anterior and posterior approach. Strikingly, the patient showed maintenance of bowel, bladder, and motor functions after surgery, thus demonstrating that nerve preservation during partial sacrectomy is a challenging but not impossible task. These commendable results are exceptional because, in most of the cases, sacrificing one or several sacral nerve roots is required to obtain free surgical margins. ${ }^{6,8-10}$ This is particularly true when tumors compromise higher segments of the sacrum and when the histological subtype demands wide excision. Indeed, patients with a middle and low sacrectomy, such as in the case described here, show better neurological function after surgery than those with a high or total sacrectomy. ${ }^{9,10}$ Lesioning $\mathrm{S} 1$ has a great impact on motor function, whereas injuries to $S 2-4$ generate high rates of bowel and bladder dysfunction, especially when both sides are affected. ${ }^{8}$ This indicates the importance of preserving as many nerve roots as possible during middle to low sacrectomy.

Several other factors can influence the remaining neurological function after sacrectomy, including age, time lapsed from the onset of disease, and preoperative neurological status. ${ }^{9}$ In our case, the patient was relatively young, had few well-controlled comorbidities, and presented with subacute neurological deficits that were potentially reversible. Also, the patient presented with a tumor that, although of a highly invasive histological subtype, was benign, spared the upper sacrum, and did not invade adjacent structures. Furthermore, the multidisciplinary evaluation and extenuating planning of the surgery, as well as the staged approach, could impact the outcomes of our patient. In this regard, the most appropriate approach to each case depends on the extension of the tumor. As such, a single posterior approach is normally used in cases of little or no presacral extension, no rectal involvement, and no large spinal defects anticipated over S2. Meanwhile, a single anterior approach could be advocated for tumors with large presacral portions and intrapelvic extension or when colostomy is needed. ${ }^{11}$ 


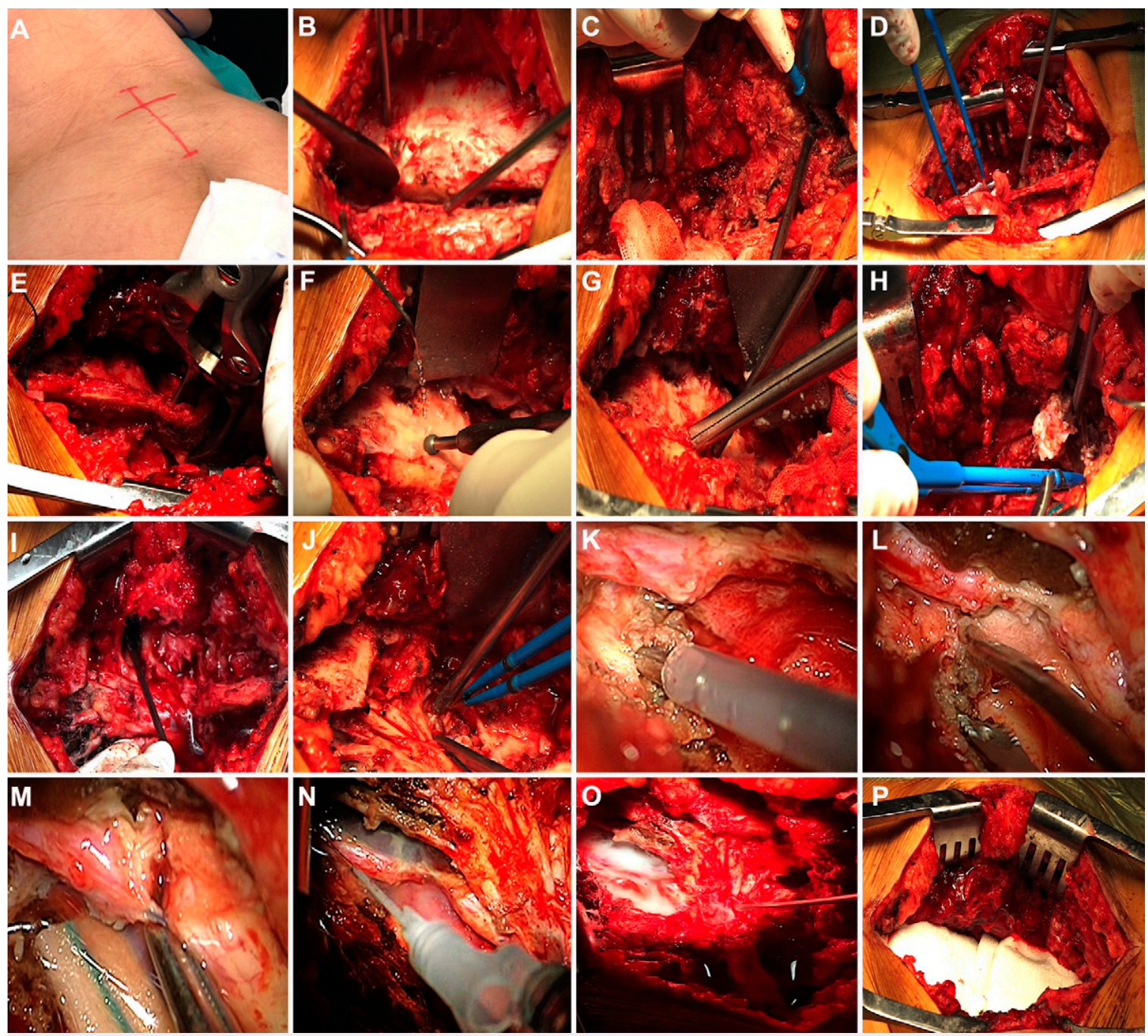

FIG. 4. Second-stage posterior approach to the sacrum for tumor resection. A: Skin incision. B: Exposure and opening of the lumbosacral fascia. C-E: Exposure of the paraspinal muscles, sacrotuberous and sacroiliac ligaments, and resection of the posterior parts of the tumor. F and G: Visualization and drilling of the posterior aspect of the sacrum. $\mathrm{H}-\mathrm{J}$ : Resection of the remaining posterior parts of the tumor and exposure of the sacral canal and plexus. $\mathrm{K}$ and $\mathrm{L}$ : Microsurgical dissection of the deeper tumor portions using a Pentero 900 microscope. M: Repairment of the right S2 root perineurium. N and 0: Repairment of a CSF leak using Beriplast $\mathrm{P}$ fibrin sealant. P: Placement of a Gelfoam sponge over the area before the closure by planes.

In our case, we decided to perform a staged anterior and posterior approach because the tumor had both intrapelvic and posterior extension. ${ }^{7}$ Although a posterior-only approach has also been proposed for sacral tumor resection, ${ }^{12}$ this procedure results in high rates of complications. Also, despite the fact that a simultaneous anterior and posterior procedure has been described, ${ }^{13}$ a staged operation, originally described by Wanebo et al., ${ }^{14}$ provides a broader exposure and facilitates spinopelvic fixation if needed. ${ }^{15}$ This approach allowed us to fully mobilize the uterus, ovaries, and bladder, protect iliac vessels, and perform colostomy during the first anterior stage, reducing the risk of complications such as bleeding, which in our case was minimal. Then, the posterior stage allowed us to perform a bicortical osteotomy, which was fundamental in achieving wide tumor excision with minimal injury of nerve roots.

The quality of the postoperative reconstruction also influences the functional status of patients. Commonly, a spinopelvic fixation is performed in all patients subjected to total en bloc sacrectomy to maintain lumbar-pelvic rotational and translational stability and restore the integrity of the pelvic ring. ${ }^{16-18}$ Nonetheless, spinopelvic fixation is challenging and carries the risk of failures due to screw breakage, loosening, or rejection of bone grafts. Furthermore, there is no consensus on whether repairing bony defects is also mandatory for patients who undergo middle to low partial sacrectomies and which is the best approach to do it. With a lack of objective tools to evaluate postoperative pelvic stability, the decision on whether to perform spinopelvic fixation may depend on the extent of sacral resection. ${ }^{19}$ In this context, our report illustrates that subtotal resection of the sacrum below S1 does not destabilize the pelvis, because both sacroiliac and lumbosacral joints remained intact. Thus, fixation was not necessary in our case.

Soft tissue defects are an important source of postoperative morbidity in patients subjected to total or subtotal sacrectomy due to the 

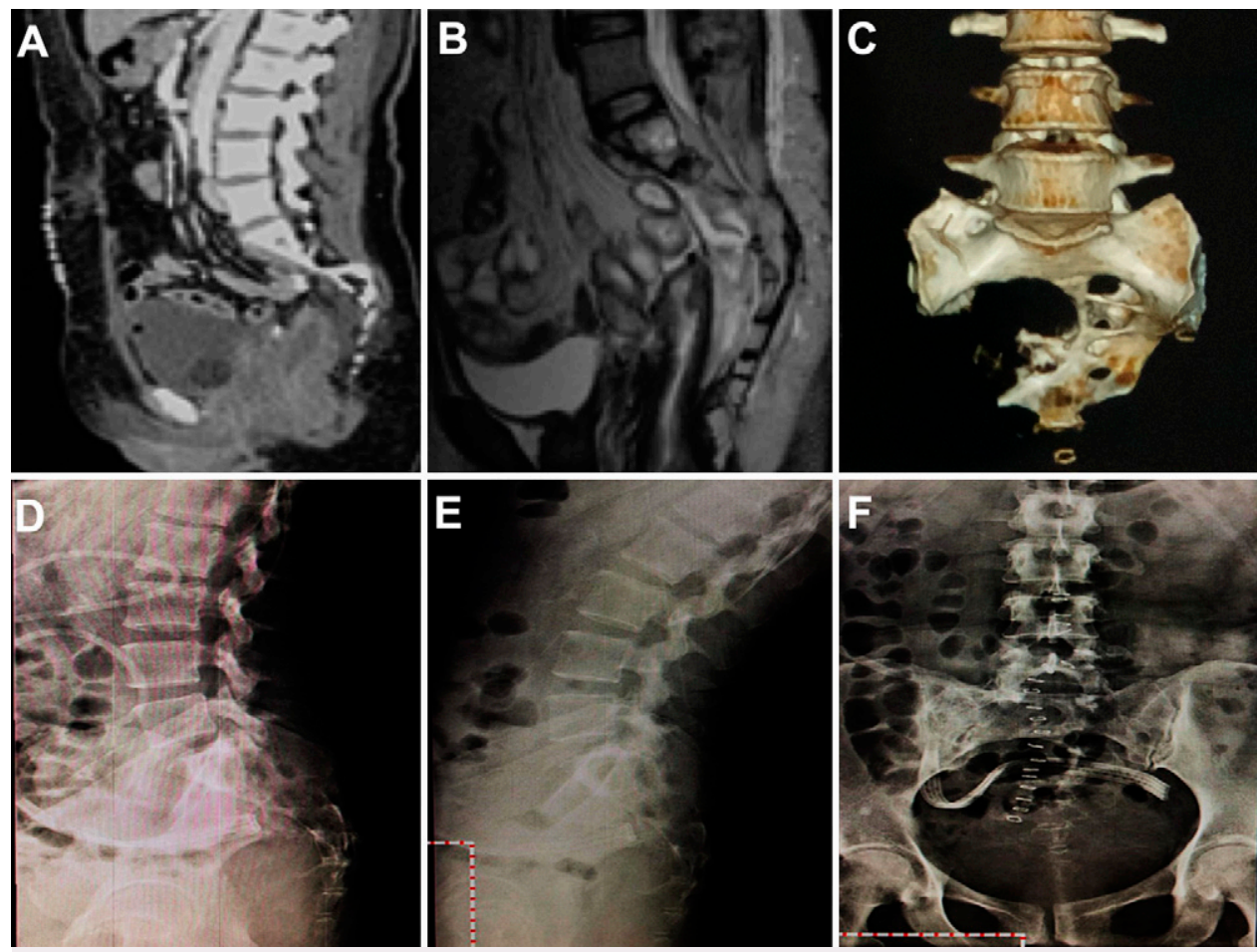

FIG. 5. Postoperative images of the pelvis and sacrum showing no residual tumor. A: Sagittal T1-weighted magnetic resonance imaging (MRI). B: Sagittal contrasted T2-weighted MRI. C: Computed tomography (CT) scan with 3D bone reconstruction; anterior view. D: Dynamic lateral X-ray image of the lumbosacral joint in flexion. E: Lateral radiographic image of the lumbosacral joint in extension. F: Abdominopelvic radiographic image showing no instability of the pelvis.

occurrence of sacral herniations of abdominal content. Commonly, the reconstruction of the posterior abdominopelvic wall is carried out using gluteus maximus, paraspinous muscle, pedicled latissimus dorsi, or vertical rectus abdominis myocutaneous flaps. ${ }^{20,21}$ Dehiscence and infection are among the complications of muscle flaps. Meanwhile, the role of synthetic nonabsorbable meshes in the reconstruction of the posterior abdominal wall is not well established. In fact, only a few studies used them with favorable results, ${ }^{21-24}$ although, in most cases, the patients received partial sacrectomies. Here, we also used a PTFE surgical mesh showing no postoperative complications directly related to the mesh. Hence, our report, together with previous studies, provides evidence in favor of synthetic meshes for the reconstruction of soft tissue defects after partial sacrectomy. However, total en bloc sacrectomies might require combined strategies using muscle flaps, meshes, and other source grafts. $20,25,26$

Finally, our case is unique because desmoplastic fibroid tumors are rarely observed in the sacrum. Indeed, these benign tumors mainly affect the mandible, femur, humerus, and pelvic bones. ${ }^{27,28}$ To our knowledge, this is the second case of a desmoplastic fibroid tumor of the sacrum. ${ }^{29}$ Hence, there is little experience with the surgical treatment and adjuvant therapy for this kind of sacral tumor.

\section{Lessons}

Surgical planning and a multidisciplinary approach are fundamental to preserve neurological function and reduce complications after partial sacrectomy. A staged abdominal and sacral approach allows good exposure of the sacrum to remove tumors with pelvic and posterior extension while allowing mobilization of viscera, blood vessel protection, and preservation of nerve roots. Spinopelvic fixation might not be required during middle to low subtotal resection of the sacrum. Synthetic nonabsorbable surgical meshes may play a role in restoring soft tissue defects and repairing the posterior abdominal wall after partial sacrectomy. Desmoplastic fibrous tumors of the sacrum are very infrequent, and there is minimal experience with their management.

\section{Acknowledgments}

We acknowledge the medical doctors and nurses of our center for their support in taking care of our patients.

\section{References}

1. Qu H, Guo W. Surgical anatomy of the sacrum. In: Guo W, Hornicek FJ, Sim FH, eds. Surgery of the Pelvic and Sacral Tumor. Springer Netherlands; 2020:165-167.

2. Zoccali C, Skoch J, Patel A, Walter CM, Maykowski P, Baaj AA. The surgical neurovascular anatomy relating to partial and complete sacral and sacroiliac resections: a cadaveric, anatomic study. Eur Spine J. 2015;24(5):1109-1113.

3. Wang J, Li D, Yang R, et al. Epidemiological characteristics of 1385 primary sacral tumors in one institution in China. World J Surg Oncol. 2020;18(1):297.

4. Chi JH, Bydon A, Hsieh P, Witham T, Wolinsky JP, Gokaslan ZL. Epidemiology and demographics for primary vertebral tumors. Neurosurg Clin N Am. 2008;19(1):1-4.

5. Rose PS, Houdek MT. Team approach: oncologic sacrectomy. JBJS Rev. 2020;8(9):e1900226. 
6. Puri A, Agarwal MG, Shah M, et al. Decision making in primary sacral tumors. Spine J. 2009;9(5):396-403.

7. Klimo P Jr, Rao G, Schmidt RH, Schmidt MH. Nerve sheath tumors involving the sacrum. Case report and classification scheme. Neurosurg Focus. 2003;15(2):E12.

8. Zoccali C, Skoch J, Patel AS, Walter CM, Maykowski P, Baaj AA. Residual neurological function after sacral root resection during enbloc sacrectomy: a systematic review. Eur Spine J. 2016;25(12): 3925-3931.

9. Moran D, Zadnik PL, Taylor T, et al. Maintenance of bowel, bladder, and motor functions after sacrectomy. Spine J. 2015;15(2):222-229.

10. Fourney DR, Rhines LD, Hentschel SJ, et al. En bloc resection of primary sacral tumors: classification of surgical approaches and outcome. J Neurosurg Spine. 2005;3(2):111-122.

11. Doty JR, Rengachary SS; AANS/CNS Joint Section on Disorders of the Spine and Peripheral Nerves. Surgical Disorders of the Sacrum. Thieme Medical Publishers; 1994

12. Zang J, Guo W, Yang R, Tang X, Li D. Is total en bloc sacrectomy using a posterior-only approach feasible and safe for patients with malignant sacral tumors? J Neurosurg Spine. 2015;22(6):563-570.

13. Localio SA, Eng K, Ranson JH. Abdominosacral approach for retrorectal tumors. Ann Surg. 1980;191(5):555-560.

14. Wanebo HJ, Marcove RC. Abdominal sacral resection of locally recurrent rectal cancer. Ann Surg. 1981;194(4):458-471.

15. Ramamurthy R, Bose JC, Muthusamy V, Natarajan M, Kunjithapatham D. Staged sacrectomy-an adaptive approach. J Neurosurg Spine. 2009;11(3):285-294.

16. Xu M, Zheng K, Zhao J, Bai WZ, Yu XC. En bloc resection and pelvic ring reconstruction for primary malignant bone tumors involving sacroiliac joint. Orthop Surg. 2019;11(6):1120-1126.

17. Kim KR, Kim KH, Park JY, et al. Surgical strategy for sacral tumor resection. Yonsei Med J. 2021;62(1):59-67.

18. Zhang HY, Thongtrangan I, Balabhadra RS, Murovic JA, Kim DH. Surgical techniques for total sacrectomy and spinopelvic reconstruction. Neurosurg Focus. 2003;15(2):E5.

19. Gunterberg B, Romanus B, Stener B. Pelvic strength after major amputation of the sacrum. An experimental study. Acta Orthop Scand. 1976;47(6):635-642.

20. Kim JE, Pang J, Christensen JM, et al. Soft-tissue reconstruction after total en bloc sacrectomy. J Neurosurg Spine. 2015;22(6):571-581.

21. Kiiski J, Kuokkanen HO, Kääriäinen M, Kaartinen IS, Pakarinen TK, Laitinen MK. Clinical results and quality of life after reconstruction following sacrectomy for primary bone malignancy. J Plast Reconstr Aesthet Surg. 2018;71(12):1730-1739.

22. Junge K, Krones CJ, Rosch R, Fackeldey V, Schumpelick V. Mesh reconstruction preventing sacral herniation. Hernia. 2003;7(4):224-226

23. Cancrini A, Bellotti C, Santoro A, Ascenzi P, Cancrini G. [Postoperative sacrocele: prevention and surgical considerations. Article in Italian. G Chir. 1997;18(10):488-492.
24. Kaplan LJ, Santora TA. Technique of sacral hernia repair. Am Surg. 1996;62(9):762-764.

25. Abhinav K, Shaaban M, Raymond T, Oke T, Gullan R, Montgomery AC. Primary reconstruction of pelvic floor defects following sacrectomy using Permacol graft. Eur J Surg Oncol. 2009;35(4):439-443.

26. Dasenbrock HH, Clarke MJ, Bydon A, et al. Reconstruction of extensive defects from posterior en bloc resection of sacral tumors with human acellular dermal matrix and gluteus maximus myocutaneous flaps. Neurosurgery. 2011;69(6):1240-1247.

27. Inwards CY, Unni KK, Beabout JW, Sim FH. Desmoplastic fibroma of bone. Cancer. 1991;68(9):1978-1983.

28. Kahraman D, Karakoyunlu B, Karagece U, Ertas U, Gunhan O. Desmoplastic fibroma of the jaw bones: A series of twenty-two cases. J Bone Oncol. 2021;26:100333.

29. Zsernaviczky J, Delling G. Desmoplastic fibroma of the sacrum. Article in German. Z Orthop Ihre Grenzgeb. 1977;115(6):962-965.

\section{Disclosures}

The authors report no conflict of interest concerning the materials or methods used in this study or the findings specified in this paper.

\section{Author Contributions}

Conception and design: Guadarrama-Ortíz, Choreño-Parra, GaribayGracián, Capi-Casillas, Salinas-Lara, Palacios-Zúñiga. Acquisition of data: all authors. Analysis and interpretation of data: Guadarrama-Ortíz, Garibay-Gracián, Capi-Casillas, Palacios-Zúniniga. Drafting the article: Montes de Oca-Vargas, Choreño-Parra, Garibay-Gracián. Critically revising the article: Guadarrama-Ortíz, Montes de Oca-Vargas, Choreño-Parra, Salinas-Lara, Palacios-Zúñiga. Reviewed submitted version of manuscript: Guadarrama-Ortíz, Garibay-Gracián, SalinasLara, Palacios-Zúniga. Approved the final version of the manuscript on behalf of all authors: Guadarrama-Ortíz. Study supervision:

Guadarrama-Ortíz, Garibay-Gracián.

\section{Supplemental Information \\ Video}

Video 1. https://vimeo.com/586247262.

Online-Only Content

Supplemental material is available with the online version of the article. Supplemental Figs. 1 and 2. http://thejns.org/doilsuppl/10.3171/CASE21384.

\section{Correspondence}

Parménides Guadarrama-Ortíz: Centro Especializado en Neurocirugía y Neurociencias México (CENNM), Mexico City, Mexico. dr.guadarrama. ortiz@cennm.com. 